\title{
LA VIEJA MEMORIA REEDITADA: QUERIDÍSIMOS VERDUGOS Y EL DESENCANTO
}

\author{
Juan Carlos Vizcaíno Martínez
}

Probablemente, una de las preguntas que habrá estado en la mente de todos cuantos han participado en la elaboración de esta publicación, haya sido plantearse si la progresiva democratización que la sociedad española vivió, a partir de la caída del régimen franquista, favoreció un caldo de cultivo lo suficientemente sólido para mejorar el nivel de la producción cinematográfica de dicho periodo. Aunque no es, ni de lejos, el tema que va a protagonizar estas líneas, personalmente manifiesto mi escepticismo en torno a ello. Creo que la rápida incorporación de un régimen de libertades no se tradujo en un auge cinematográfico. Personalmente, considero que la democratización del país posibilitó una liberalización formal, abriendo la presencia de intenciones y temáticas que hasta entonces solo se habían permitido de manera simbólica o solapada. En este caso, se contravino la máxima cinematográfica de Jacques Tourneur - «sugerir antes que mostrar»-, optándose en líneas generales por lo obvio, por mostrar aquellos elementos que hasta entonces tenían que resultar mitigados -especialmente centrados en la moda del «destape»—, sin que esta epidérmica y oportunista tendencia tuviera más incidencia que la meramente sociológica.

Creo por ello que, en su conjunto, la década de los setenta no tuvo, cinematográficamente hablando, la importancia del decenio precedente, en donde con la consonancia de la influencia de las corrientes renovadoras del conjunto de países europeos —Francia, Inglaterra y, muy especialmente, Italia-, nuestro país vivió uno de los periodos más fértiles de su andadura fílmica — cierto es, con menor incidencia y repercusión que en los países citados-. Es probable, a este respecto, que a la hora de apuntar una razón de peso para explicar ese descenso de interés, más allá de citar la fagocitación de la generación de directores emergida en los sesenta, o la absorción de una parte sustancial de su producción, en los senderos del subproducto en diversas de sus vertientes y géneros ${ }^{1}$, quizá cabría apuntar como un elemen-

1 En el análisis de las claves de tan amplia producción, cabría recomendar la lectura del libro Cine español: cine de subgéneros, publicado en 1975 por la editorial Fernando Torres, de Valencia, y elaborado en sus contenidos por el equipo de redacción de Cartelera Turia. 
to de especial significación ese progresivo y ya nunca postergado alejamiento con la realidad de esa sociedad transmutada de rural a urbana, que definió buena parte de las mejores propuestas de nuestro cine. Algo que se manifestó de forma muy especial y significativa en la comedia española —esa corriente del sainete, heredada de la influencia italiana, tan cercana en su personalidad a la nuestra-, y que se extendió al conjunto de nuestra expresión fílmica en todas sus vertientes.

En cualquier caso, entre los elementos que definieron el cine tanto de los últimos años del periodo franquista, como en los primeros exponentes de la recién nacida democracia, hubo una vertiente genérica de especial interés, quizá no muy numerosa en su producción, pero indudablemente representativa en su interés, no solo por la específica calidad de sus propuestas, sino por esbozar quizá la mirada revisionista más atractiva que manifestó nuestra producción cinematográfica en aquellos años. El excelente comentarista cinematográfico Miguel Marías la describía así:

Se produjo un misterioso y pronto frustrado acercamiento al documental, a la encuesta cinematográfica, empleando equipos ligeros: ahora que no había obstáculos, algunos se lanzaron a tratar de encontrar y desvelar la realidad del país, sepultada o reprimida, disimulada y maquillada, a unos recién estrenados ciudadanos libres que se suponía ansiosos de verse reflejados tal como realmente eran (Marías, 1998: 112).

Evidentemente, me estoy refiriendo a ese inesperado ciclo de películas que entremezclaban el docudrama y el montaje documental, con la recopilación de imágenes que posibilitaran la memoria y la reflexión sobre acontecimientos, temáticas y hechos relevantes de ese pasado que se centraba en episodios de la dictadura franquista, hasta entonces vedados en su manifestación visual. Probablemente la consolidación de dicho subgénero -en el que en bastantes ocasiones los testimonios de testigos de los hechos y sucesos narrados alcanzaban un especial protagonismo-, tuvo su punto de partida con el enorme éxito de Canciones para después de una guerra (1971, Basilio Martín Patino). Sin embargo, ello no fue más que la punta del iceberg para la relativa proliferación de exponentes de esta tendencia. Películas como Queridísimos verdugos (1977) y Caudillo (1977), ambas firmadas por el propio Martín Patino — verdadero especialista en dicha vertiente-, La vieja memoria (1976, Jaime Camino), Raza, el espíritu de Franco (1977) y El asesino de Pedralbes (1978) y que quizá tuvo su propuesta más atrevida en El desencanto (1976, Jaime Chávarri). Como antes señalaba, no nos encontramos con una amplia producción en este terreno -en el que no faltaron incluso propuestas apologéticas del régimen -auspiciadas por ese pintoresco personaje llamado Eduardo Manzanos-. Ni siquiera podemos decir que en décadas precedentes este subgénero no había sido utilizado en nuestro cine — se encuentra el ejemplo referencial de la apología franquista firmada por José Luís Sáenz de Heredia en 1964 con Franco, ese hombre, destinada a exaltar la figura del dictador con motivo de los denominados «25 años de paz», o en la olvidada tentativa que Manuel Summers expresó con la revisable Juguetes rotos (1966).

Sin embargo, lo cierto es que cabe referirse a la tan efímera como reiterada apuesta por ese sendero, como el quizá más provechoso, atrevido y sincero brindado por nuestro cine a la hora de plantearse una mirada crítica sobre las consecuencias que el franquismo 
tuvo en la sociedad española. Una mirada que en ocasiones recibió la acusación de teñirse de nostalgia - las propuestas de Martín Patino con Canciones... y Caudillo-, que también vivió en otras la fortuna de la repercusión comercial —Canciones... y El desencanto supusieron, sobre todo en el segundo de los ejemplos citados, un notable ejemplo de éxito de público y crítica. Ni que decir tiene que la llegada a las pantallas de todas estas producciones en no pocos casos revistió enormes dificultades, llegando en algunos casos —nuevamente el de Canciones..., rodada en 1971 y estrenada en 1976- y Queridísimos verdugos _rodada en 1973 y no considerada simplemente existente como tal película hasta $1977^{2}$ - a registrar bastante tiempo entre su gestación y el estreno comercial más o menos normalizado, por lo general en salas especializadas. Afortunadamente, estos retrasos, estos inconvenientes marcados por diversos estamentos de las instituciones terminales franquistas o las comprendidas en el periodo de transición, creo que en modo alguno perjudicaban la esencia o los objetivos de todas estas películas, cuyo conjunto calificaba con gran sagacidad Carlos Losilla como «un mastodóntico intento de recuperación de la memoria colectiva de todo un país» (Losilla, 1996: 81).

¿Con qué títulos de dicha corriente cabría, pues quedarse? Difícil coyuntura se plantea, en la medida que su mirada conjunta resulta sorprendentemente complementaria a nivel temático y en sus propias cualidades, pese a resultar divergentes en métodos y estilos, ofreciendo en un conjunto un insospechado ciclo de sinceridad documental y de recreación histórica, tamizado por rasgos de estilo y técnica propios de las intenciones de cada uno de sus artífices. Sin embargo, estas líneas se centrarán en el análisis más o menos sucinto de dos de los títulos que, bajo mi punto de vista, pudieron representar puntos de vista contrapuestos a la hora de esa mirada retrospectiva al pasado reciente de un país, que se preparaba para recibir la llegada de un régimen de libertades y que, precisamente por esa misma circunstancia, debía de reencontrarse con un ayer lleno de sombras y claroscuros. Sé que es una elección muy personal, pero de todas estas realizaciones, apuesto en esta ocasión por Queridísimos verdugos y El desencanto. La primera de ellas por su rotundidad y atrevimiento - quizá personalmente me resulte la pieza más valiosa, al tiempo que olvidada, de las logradas dentro de este contexto-, mientras que la segunda se incorpora por la originalidad de sus planteamientos, el contraste de enfoques que ofrece con el título antes mencionado de Martín Patino, planteando una propuesta en la que la visión de un entorno general, vendrá tamizada por una apuesta por el docudrama de una familia en la que, curiosamente, las contradicciones de la vida franquista se planteaban de forma pertinente. Ni que decir tiene que la repercusión lograda en ambos casos fue muy dispar. Queridísimos verdugos estuvo durante varios años retenida hasta que logró estrenarse, recibiendo una relativa indiferencia de la crítica, mientras que el film de Jaime Chavarri cosechó ese ya señalado inesperado éxito de público, facilitando el posterior desarrollo de su progresivamente decreciente andadura como realizador.

2 Antonio Castro relata en su reseña de la película publicada en el № 44 de la revista Dirigido por.. (mayo de 1977), el hecho de que la película se produjo con la financiación de la Fundación Gulbenkian. Ello le permitió tener la película finalizada y retenida — en el año de su rodaje jamás hubiera sorteado la censura franquista-, hasta que unas circunstancias más propicias le permitieran su acceso a las pantallas, como así sucedió. 


\section{LA ESPAÑA PROFUNDA: QUERIDÍSIMOS VERDUGOS (1973 / 1977)}

En el ámbito concreto del cine español, me tendría que remitir hasta el célebre cortometraje Las Hurdes / Tierra sin pan (1932, Luis Buñuel) para encontrar una producción que profundice en esa España negra que - mal que nos pese- aún nos acompaña. Como si se tratara de los célebres grabados de Goya, considero la película de Basilio Martín Patino como una de las propuestas más perturbadoras de la historia de nuestro cine. A partir de la filmación, el testimonio, la reunión y la propia visión de sus personalidades, las imágenes de este documental recuerda la andadura de los tres verdugos con que contaba la administración española en el momento de la plasmación de este proyecto — primeros años setenta-

Tres hombres de baja extracción cultural que en el relato de sus vidas procedieron del estraperlo, incluso el robo en su juventud. La precisión de las imágenes y sus relatos dejan espacio abierto para la reflexión; quizá de haber mediado en ellos otras circunstancias, podrían haber sido ellos mismos candidatos para usuarios de sus propios servicios en el garrote vil, modelo oficial de pena de muerte en la España franquista tras haber sido abolida esa condena en la II República. Los protagonistas de este recorrido son Antonio López, Vicente Copete y Bernardo Sánchez. Personas curtidas, perfectos ejemplos de ese sector rural y de un país sumido en el retraso cultural. La mirada de Martín Patino es seca, concisa, mostrando el especial interés del perfil psicológico del tercero de ellos. Un extraño hombre de semblante sombrío y siniestro y aspecto exterior de capo mafioso, caracterizado por sus actitudes nihilistas y su facilidad para torpes pareados - falleció antes incluso de la conclusión de la película-. Ellos son los enlaces para ese repaso a una crónica negra de seres desgraciados, en buena medida surgidos de ambientes pobres y conflictivos -es especialmente dolorosa la historia del joven criminal de Gandía, su entorno familiar, el desarrollo de la petición de clemencia en plenas navidades y la ejecución final de la sentencia_- y a los que acciones lamentables privan de vida. Toda una relación causa / efecto que se complementa en el documental con el inserto de artículos y titulares de prensa — quizá en demasiada medida—, grabados, algunos testimonios de personajes implicados, juristas e incluso psicólogos. El desarrollo de la filmación no omite el origen de la aplicación del garrote vil — sustituyendo a la horca por orden de Fernando VII-, la historia de su pretendido carácter ejemplarizador y el ascendente que su aplicación pública tuvo siempre entre la población.

Pero el sobrecogedor documento de Martín Patino va más allá. Logra ser espeluznante en la descripción que se efectúa de la aplicación de esta forma de asesinato legal —afortunadamente ya parte del pasado en nuestro país-. En concreto resulta especialmente impactante el relato de un veterano psicólogo - el doctor Velasco-Escassi- que confiesa incluso haberse «sentido sucio» al presenciar y de alguna manera legitimar socialmente, la condena de un joven muchacho. Lo que en un momento determinado se denomina como «la muerte artesanal», incluso tiene sus elementos de contradicción entre la presunta pericia de los verdugos y el testimonio de algunos de los testigos de ciertas ejecuciones que relatan la tortura que sufrieron algunos de los condenados. Al fallar inicialmente los «infalibles» resultados del garrote vil.

Mas allá de su inapelable documento en contra de la pena de muerte -conclusión esta que jamás se esgrime directamente pero queda manifiesta en todos sus fotogramas-, la otra gran virtud de este documental estriba en su extraordinaria capacidad de observación. 
La cámara de Martín Patino sabe escudriñar entre las estancias, los rincones, los objetos de decoración incluso, de todos los personajes que aparecen en ella. Da igual que en la casa de uno de los verdugos se ofrezcan insertos de muñecos, cuadros y demás elementos, o que en las escenas de algunos de los juristas que aparecen - por más que alguno se manifieste en contra de la aplicación de la pena de muerte en casos concretos- se entrevea una retórica e incluso una "puesta en escena» franquista. Sin embargo, es evidente que las imágenes de Queridísimos verdugos ofrecen un retrato en ocasiones insoportable de ver sobre todo por la cercanía que trasladan de un país retrasado, dominado por la incultura, y con una serie de atavismos - flamenco, afición a los toros, etc.- que quizá hayan evolucionado con el paso de unas tres décadas, pero aún resultan parte de nuestra cultura.

Puede que a mi juicio sobren en esta película las explicaciones didácticas sobre la genética de los comportamientos delictivos -es un elemento que desmerece por la evidencia de las imágenes-, que sus instantes finales sean innecesariamente metafóricos, y que quizá el ritmo no esté en todo momento a la misma altura. Sin embargo, creo que esta película de Basilio Martín Patino supera tanto a las citadas Canciones para después de una guerra y Caudillo - ambas también muy interesantes-y debería de adquirir un permanente reconocimiento como una de las propuestas más inquietantes de toda la historia de nuestro cine. Cuando en los tiempos que corren cualquier film fácilmente desmontable adquiere un injustificado apoyo mediático, creo que sería de justicia valorar en la medida que merece una película valiente, rodada en plena dictadura franquista y cuya visión de un país subdesarrollado pese a sus apariencias de progreso es realmente honda, centrando además su incidencia en uno de los pilares más oscuros en los que se basó el carácter represivo de su sociedad. Solo por esta película, más cerca de lo apasionante que de lo discutible, Basilio Martín Patino debería ser considerado uno de los grandes outsiders de nuestra cinematografía.

\section{LA GRAN FAMILIA. EL DESENCANTO (1976)}

El film de Jaime Chavarri ofrece un elemento inicial de enorme atractivo; su propuesta dramática se articula en base a la figura de alguien que no estará presente físicamente en el relato. A partir de la rememoranza del poeta Leopoldo Panero - una figura de notable relieve en el entorno cultural cercano al franquismo-, la película se articulará como una especie de huis cluis puesto en práctica por las confesiones de su viuda, Felicidad Blanch, y los tres hijos del matrimonio: Juan Luis, Michi y Leopoldo María. La interacción de sus evocaciones marcará la plasmación de un universo aparentemente refugiado en la normalidad familiar, pero que con rápida pertinencia se expresará como un auténtico exorcismo sobre el anquilosamiento, la hipocresía y la falsedad demostrada en el entorno familiar, especialmente centrado en un contexto autoritario, provinciano, aunque en este caso se manifieste a través de un contexto mas o menos «ilustrado» o influenciado por la inquietud cultural. En este caso, será fácil de detectar que esa circunstancia, ese plus de relativo intelectualismo, solo contribuirá para atenuar las formas, para vestir de cierto alcance civilizado y apariencia de seriedad, lo que quizá en otra familia de menor bagaje intelectual, quizá ubicada a escasos kilómetros de donde se situaba la finca de los Panero, se expresaría con un contexto dominado por la violencia, el primitivismo o los malos tratos. En ese sentido, como en muchos otros, Queridísimos verdugos y El desencanto pueden plantear las dos caras de la misma moneda. Sin embargo, la singularidad de la propuesta de Chavarri se centra en su particular huída de cualquier expectativa por 
parte del espectador, internándose en los meandros de una progresión narrativa dominada por las rupturas tonales, lo abrupto de su montaje, y la combinación de factores externos. Contra lo que podría ser más previsible, esos contrastes —en ocasiones demasiado evidentes-, no solo no se erigen como lastres en la homogeneidad de su conjunto, sino que logran proporcionar al mismo su definitiva personalidad. Es así, como con esa mezcla de «interpretación» que efectúan sus diferentes personajes-actores, el relato más o menos desordenado de sus circunstancias y recuerdos, o la oportuna presencia de Leopoldo María en el metraje logran, contra lo que podría intuirse, ofrecer a El desencanto esa patina de singularidad, de buscada espontaneidad, a la que ayuda no poco la fuerza que imprime su sombría tonalidad fotográfica en blanco y negro. La suma de estos factores es lo que ha permitido que el paso del tiempo haya otorgado a la película la merecida consideración de una de las propuestas más atractivas del cine español de toda la década.

La extraña radiografía de la familia Panero -inicialmente planteada como un cortometraje-, tiene la sorprendente cualidad de su equilibrio. Un equilibrio que permite la paradoja de mostrar el fracaso —el desencanto—, de una familia considerada inicialmente como ejemplar para el régimen franquista, y en cuyas grietas y fisuras se expande no solo la caducidad de unos modelos sociales que, probablemente, nunca resultaron efectivos, y generalmente estuvieron encubiertos por la hipocresía y el autoritarismo. Pero bajo mi punto de vista, la vigencia de la película viene dada por el hecho de no detenerse en esa premisa de partida. Hay en sus fotogramas espontáneos y rebuscados al mismo tiempo, en esas presencias tan honestas como histriónicas de los componentes de la familia, una sensación de introducirse en el secreto arcano de un colectivo que tuvo la lucidez de mostrar la intimidad y fragilidad de sus vivencias y emociones, con una intensidad como pocas veces se ha podido contemplar en la pantalla. Quizá uno puede dejar de lado esa cadencia casi de recitado impostado que esgrimirá en alguna ocasión Felicidad Blanc, pero en contrapartida hay momentos cuya intensidad en la confrontación de reproches llega a resultar insoportable. En este sentido, las secuencias en las que comparten sus puntos de vista Felicidad y sus hijos Leopoldo María y Michi revisten, especialmente con los lúcidos reproches del mayor de los hijos, una inusitada sensación de molesta carga de profundidad de hijo a madre, que la progenitora asumirá con la mayor comprensión y capacidad autocrítica posible.

Valiente, honesta, descompensada y, por momentos, fascinante, El desencanto supone un auténtico islote en el devenir de nuestro cine, que tuvo su continuidad casi dos décadas después con la —al parecer- muy atractiva continuidad que plasmó el casi inencontrable Después de tantos años (1994) realizada por Ricardo Franco. Un epílogo cinematográfico que marca la azarosa andadura de la familia -Michi falleció en un entorno de casi miseria en 2004, Leopoldo María sobrelleva su tormentosa existencia alternando una obra poética de culto... ${ }^{3}$. Lo cierto es que las provocadoras y, por momentos, hipnóticas imágenes del film de Chavarri, más allá de su precisa situación, revelan el fracaso del modelo tradicional de la familia. En ese sentido, su alcance revelador es tan incuestionable como plenamente vigente en nuestros días, y me gustaría traer hasta aquí dos opiniones reveladoras, formuladas años después; las de los estupendos comentaristas José Ma Latorre y Carlos Losilla: «El desencanto me sigue pareciendo la mejor película de Jaime Chavarri hasta el momento y una de las pro-

3 Un relato evocativo del destino de los componentes de la familia Panero fue relatado por Luís Antonio de Villena en el artículo «Los Panero», publicado por el diario El Mundo del 27 de febrero de 2008 (p. 54). 
puestas más inteligentes del cine español de estos últimos años» (Latorre, febrero 1983:18); «El desencanto... es seguramente una de las películas más modernas de nuestra transición» (Losilla, julio-agosto 1996:82).

\section{MEMORIA CINEMATOGRÁFICA EN TIEMPOS CONVULSOS Y REVISIONISTAS}

El modelo cinematográfico expuesto en estas líneas ha dejado en evidencia una curiosa circunstancia, que dejo en el aire para un análisis posterior de mayor profundidad. El hecho no es otro que comprobar la recurrencia de su modelo en momentos y situaciones en donde la tensión social española alcanzará — por medio de algunos de los exponentes de su sociedad- una mayor virulencia. En este sentido, títulos más o menos recientes como Rejas en la memoria (2004, Manuel Palacios) —sobre los presos republicanos en periodo franquista-, o las controvertidas La pelota vasca. La piel contra la piedra (2003, Julio Medem) —que intenta analizar el conflicto territorial vasco- y Hay motivo (2004, varios) —oponiéndose a la política del Partido Popular-, son ejemplos pertinentes de este enunciado. Sin embargo, sí me gustaría finalizar estas líneas con una referencia muy especial. Se trata de consignar, recordar y, en buena medida, situar en su justa medida, la presencia de una propuesta enmarcada dentro de estas características, que realmente se atrevió a mostrar con contundencia, implicación casi física y capacidad para estar presente en los momentos incluso más delicados, la verdadera confrontación registrada en la sociedad española con el advenimiento de la democracia. Me estoy refiriendo, lógicamente, al magnífico díptico rodado por los hermanos Cecilia y Juan José Bartolomé, quienes con Después de... - No se os puede dejar solos y Atado y bien atado_ (ambas de 1983), puede decirse que lograron plasmar en la pantalla la auténtica complejidad social de este proceso. Las enormes dificultades que tuvieron que sortear a la hora de llevar a buen fin este proyecto no han de suponer, en este caso, más que un motivo suplementario de reconocimiento hacia uno de los testimonios más valiosos, directos y reveladores de un periodo reciente de nuestra historia reciente. Un periodo este que aunó interés y necesidad al mismo tiempo y que diversas figuras cinematográficas supieron preludiar con tanta disparidad aparente de métodos, estilos y temáticas pero que, en el fondo, confluyeron en una voluntad de testimonio digna de verdadero elogio.

\section{BIBLIOGRAFÍA}

MARÍAS, Miguel, «El cine español de los años 70», Comisaría General de España en Expo Lisboa '98. Clásicos y modernos del cine español, 1998, pp. 107-124.

CASTRO, Antonio, "Queridísimos verdugos», Dirigido por..., n 44 (mayo, 1977), p. 30.

LATORRE, José $M^{\mathrm{a}}$, «Caballero de Astorga, poeta del franquismo», Dirigido por..., $\mathrm{n}^{\circ} 102$ (marzo, 1983), pp. 18-19.

LOSILLA, Carlos, «El desencanto». Dirigido por..., n² 248 (julio / agosto, 1996), pp. 81-82.

VILLENA, Luís Antonio de, «Los Panero». El Mundo. 27 de febrero de 2008. p. 54. 